\title{
Improvement of productivity and quality of entrepreneur Bika Bakar in
}

\section{Medan city}

\author{
Arif Qaedi Hutagalung ${ }^{1 *}$, Aryanti Sariartha Sianipar ${ }^{2}$, Doli Muhammad Jafar \\ Dalimunthe $^{3}$ \\ ${ }^{1}$ Fakultas Ekonomi \& Bisnis, Universitas Sumatera Utara \\ email* : arifqd@usu.ac.id
}

\begin{abstract}
In Community Service activities, partners are Bika Bakar business actors in Medan City. The business partner has been engaged in the culinary sector, especially traditional cake type foods since 1990. The type of cake food produced by this business partner is baked bika cake. The production process is carried out at home with the help of several employees and equipment that is still simple, does not have accountancy, packaging that still uses plastic bags and limited access to marketing. Promotions that are lacking make partner products unable to compete with cake products produced by large businesses. Partners still use simple tools so that the production of bika bakar is not optimal in quantity and quality of production, so that Ms. Nurmalis' roasted bika is still less popular than cakes with well-known brands. Improvement in designing good simple bookkeeping in financial management. Increasing the quality and quantity of Bika Bakar production after the addition of a furnace and an increasing number of bika cake molds and using good paper bags, as well as product development through making brands in Bika Bakar Mitra products and online marketing.
\end{abstract}

Keywords: Bika Bakar, Productivity, Quality, and Brand

\begin{abstract}
Abstrak
Dalam kegiatan Pengabdian Masyarakat yang menjadi mitra adalah pelaku usaha Bika Bakar di Kota Medan. Mitra usaha bergerak di sektor kuliner khususnya makanan berjenis kue tradisional sejak tahun 1990. Jenis makanan kue yang diproduksi oleh mitra usaha ini adalah kue bika bakar. Proses produksi dilaksanakan di rumah dengan bantuan beberapa pegawai dan peralatan yang masih sederhana, belum memiliki pembukuan yang rapi, kemasan yang masih menggunakan plastik kantongan serta akses pemasaran yang masih terbatas.

Promosi yang kurang membuat produk mitra belum dapat bersaing dengan produk kue yang diproduksi usaha yang sudah besar. Mitra masih menggunakan alat yang sederhana sehingga produksi bika bakar yang dihasilkan belum optimal dalam kuantitas maupun kualitas produksi, sehingga bika bakar Ibu Nurmalis masih kurang popular dibandingkan kue dengan merek yang sudah terkenal.

Peningkatan dalam merancang pembukuan sederhana yang baik dalam pengelolaan keuangan. Peningkatan kualitas dan kuantitas produksi Bika Bakar setelah penambahan tungku api dan cetakan kue bika yang bertambah dan memakai paper bag yang baik, serta pengembangan produk melalui pembuatan Merek di produk Bika Bakar Mitra, dan pemasaran online.
\end{abstract}

Kata kunci : Bika Bakar, Produktifitas, Kualitas, dan Merek

\section{Pendahuluan}

Pemberdayaan usaha mikro, kecil dan menengah (UMKM) merupakan langkah yang strategis dalam meningkatkan dan memperkuat dasar kehidupan perekonomian di kota medan 
khususnya melalui penyediaan lapangan kerja untuk mengurangi tingkat kemiskinan dan pengangguran. kota medan selama ini dikenal sebagai dikenal dengan nama Tanah Deli dan memiliki istana kerajaan yaitu Istana Maimun 25 Agustus 1888 M. Hal ini merupakan peluang dalam meningkatkan sektor perekonomian masyarakat di Kota Medan dengan memanfaatkan potensi antara lain dalam bidang usaha makanan ringan yang dapat dijadikan oleh-oleh bagi para wisatawan yang melintas dan tentu saja merupakan peluang usaha dan investasi dalam perekonomian masyarakat di kota medan yang dominan meliputi Industri kecil yang berbasis pertanian, perkebunan, perikanan serta industri rumah tangga (home industries)

Dalam beberapa tahun belakangan ini industri kecil terutama industri rumah tangga tumbuh dan berkembang di Kota Medan, hal ini ditunjukkan dengan banyaknya jenis makanan ringan khas kota Medan diantaranya Bika Ambon Zulaikha, Bolu Meranti dan Durian Ucok. Namun ada juga bika lainnya yang kurang di kenal sebagai makanan khas dari kota Medan yang merupakan industri rumah tangga salah satunya adalah industri rumah tangga makanan ringan yang dinamakan Bika Bakar yang rasanya enak dan gurih. Bika Bakar ini biasanya dijadikan oleh-oleh, cemilan atau hidangan untuk perayaan hari besar keagamaan seperti Idul Fitri, Tahun Baru, atau untuk santapan berbuka puasa. Pelaku usaha berada di kota Medan dan produk yang dihasilkan berupa olahan tepung beras dan kelapa yang rasanya gurih, asin dan enak.

Adapun mitra pertama dalam pengabdian ini adalah produsen Bika Bakar bernama Ibu Nurmalis yang berada di Jl. Amaliun kelurahan kota matsum III Kecamatan Medan Kota yang mereka produksi di pasaran. Bika Bakar ini merupakan proses dari bahan bahan seperti tepung beras yang sudah dicampur kelapa dan gula diaduk-aduk kemudian dimasukkan ke cetakannya yang mirip mangkok terbuat dari daun pisang.

$\mathrm{Bu}$ Nurmalis dalam kegiatan produksi kue bika bakar hanya terbatas kepada beberapa konsumen yang pernah memesan dalam jumlah tertentu pada acara-acara tertentu atau produksi untuk di jual dipasar. Sehingga para konsumen mengetahui adanya bika bakar hanya dari informasi melalui konsumen lain yang telah merasakan bika bakar ini. Sebenarnya Ibu Nurmalis sudah menerapkan pemasaran Word Of Mouth tetapi informasi Bika Bakar Bu Numalis masih jauh dari harapannya.

Dari informasi yang telah pengusul kumpulkan, jika dilihat dari produksinya bika bakar Ibu Nurmalis dapat diproduksi sebanyak $5 \mathrm{~kg}$ sampai $6 \mathrm{~kg}$ per hari dan penjualan tersebut hanya kepada konsumen dipasar. Bika bakar juga dapat dipesan untuk oleh-oleh namun tidak dapat di pesan dengan banyak dan cepat karena tenaga kerja yang ada hanya terbatas serta alat-alat penunjang produksi seperti tungku masak yang digunakan sebagai alat hanya seadanya.

Penyebab laris manisnya kue Bika Bakar Ibu Nurmalis ini di era munculnya makananmakanan modern, karena masyarakat menilai masakan tradisional lebih aman ketimbang makanan yang modern atau makanan-makanan luar yang cenderung menggunakan pengawet dan bahan-bahan kimia lainnya.

Mitra usaha Bika Bakar berkeinginan kuat untuk mengembangkan hasil usahanya namun masih mengalami banyak permasalahan yang dihadapi mitra seperti ketidakmampuan dalam mengembangkan pangsa pasar dan terkendala pada peningkatan produktifitas usahanya, Mitra hanya melakukan pemasaran dengan konsumen yang sudah pernah membeli bika bakarnya dan 
bagi orang yang ingin membeli produk tersebut dengan jumlah banyak sangat susah juga karena bika bakar diproduksi hanya terbatas saja, selain itu Ibu Nurmalis belum membuat merek bika bakarnya secara jelas hanya tulisan di stelling jualan dengan huruf kecil melalui sticker sehingga para konsumen yang ingin membeli juga terlihat.

Sementara dari packaging kue bika bakar tersebut masih menggunakan kantongan plastik yang kurang higienis dan berbahaya dari segi kesehatan dan juga apabila ada pesanan dalam jumlah banyak untuk dibawa ke luar kota, Ibu Nurmalis belum memiliki kotak packaging untuk memenuhi permintaan tersebut.

\section{Metode Pengabdian}

Untuk dapat membangkitkan produksi dan penjualan Bika Bakar yang berada di Kota Medan maka perlu untuk dilakukan pengabdian kepada para mitra yaitu pelaku usaha bika bakar. Tim pengusul pengabdian sebagai bagian civitas akademik, merasa terpanggil untuk ikut membantu memberikan solusi terhadap permasalahan yang dihadapi Ibu Nurmalis (pelaku usaha Bika Bakar). Berdasarkan survey dan wawancara kepada pelaku usaha, tim pengabdi mencoba menawarkan solusi dari sisi manajemen yang masih dialami pelaku usaha Bika Bakar, yaitu pembukuan sederhana dan peningkatan produksi.

Manfaat yang diperoleh mitra dari pelaksanaan pengabdian masyarakat tersebut, diantaranya :

1. Ibu Nurmalis (Pelaku Usaha Bika Bakar) dapat membukukan semua transaksi dengan baik sehingga pengelolaan keuangan dapat diketahui dengan jelas. Selain itu pencatatan bahan baku dan produksi kue yang dalam hal ini agar mitra dapat memprediksi kebutuhan konsumen yang ingin membeli bika bakar tersebut.

2. Mempermudah mitra dalam pembuatan Laporan laba / rugi usaha.

3. Meningkatkan kualitas dan kuantitas produksi bika bakar untuk dapat bersaingdalam memperluaspasar.

4. Mitra usaha akan memahami pentingnya merek dan pemasaran online dalam meningkatkan penjualan bika bakar tersebut.

5. Mitra usaha akan memahami manfaat pentingnya packaging dalam meningkatkankualitas dan higienis guna meningkatkan kepercayaan konsumen bikabakar.

6. Meningkatkan kualitas SDM dan mempersiapkan metode pelatihan untuk tenaga kerja yang siap kerja untuk mitrausaha.

Metode yang diterapkan pada pengabdian ini terdiri dari beberapa pelatihan bagi mitra, dimana pelatihan dimulai dengan bagaimana cara sederhana dalam membuat/ menyusun laporan keuangan sederhana. Manfaat yang didapat dalam pelatihan ini adalah mitra jadi tahu dan mengerti bahwasannya laporan keuangan sangat diperlukan dalam menjalankan bisnis. Menurut Kasmir (2014) $)^{[1]}$ laporan keuangan adalah laporan yang menunjukkan kondisi keuangan perusahaan pada saat ini atau dalam suatu periode tertentu. Hal inilah yang akan kami lakukan karena Bu Nurmalis menjalankan bisnisnya sama sekali tidak mencatat dalam bentuk laporan keuangan dan laporan laba rugi juga tidak tercatat. 

Jafar

Metode berikutnya dengan membuat pelatihan dalam strategi pemasaran khusus untuk pembuatan merek dan packaging. Menurut Kotler dan Armstrong (2012) ${ }^{[2]}$ Atribut Produk adalah pengembangan suatu produk atau jasa melibatkan manfaat yang akan ditawarkan produk atau jasa tersebut. Pelatihan ini dilakukan agar Bu Nurmalis dapat menciptakan/membuat merek di usaha bika bakarnya sehingga usaha bika bakarnya dapat dikenali masyarakat pada saat ingin membeli produk tersebut. Selain itu perubahan packaging juga akan mempengaruhi tampilan yang lebih menarik dan bika bakarnya juga lebih baik lagi dalam penyajian dan kesehatan bagi konsumen.

Yang terakhir metode yang dipakai adalah pelatihan dalam peningkatan kuantitas dan kualitas produk bika bakar, pemanfaatan teknologi agar dapat bersaing dan menciptakan kuantitas produk untuk memenuhi kebutuhan konsumen (Suryana,2014) ${ }^{[3]}$. Mitra akan memnerima bantuan dalam meningkatkan kuantitas produksi bika bakar yaitu 2 tungku Api yang sudah ditempah sebesar 20inci, dan penambahan alat cetakan kue bika, serta tenda yang berguna untuk konsumen yang ingin makan di tempat.

\section{Hasil dan Pembahasan}

Untuk menyelesaikan permasalahan yang ada pada pelaku usaha Bika Bakar, maka kami melaksanakan kegiatan pelatihan tersebut serta pendampingan kepada pelaku usaha agar usaha tersebut dapat berkembang dengan merek yang baru dan produktifitas kualitas dari kue Bika Bakar juga meningkat.

Permasalahan yang pertama yg terjadi selama ini dalam hal pembukuan keuangan mitra usaha,selain itu mitra juga menyatakan bahwa masih kurang memahami tentang hutang dan piutang karena selama ini mitra usaha sering sekali memberikan piutang bagi konsumen atau orang yang membeli produknya tetapi banyak yang tidak bayar karena lupa mencatat dan menagih ke konsumen tersebut. Oleh sebab itu kami memberikan pelatihan mengenai pembukuan sederhana dan teori tentang istilah-istilah yang ada dalam akuntansi yang bertujuan agar mitra usaha dapat mengetahui dalam penyusunan laporan keuangan yang baik, seperti penentuan nilai debet dan kredit.

Pelatihan pembukuan sederhana ini juga akan mempermudah bagi mitra dalam menghitung seberapa besar keuntungan yang telah didapatkan dan juga seberapa besar biaya yang telah dikeluarkan. Mitra usaha juga diberikan latihan kasus dalam pembukuan dalam menyusun laporan laba rugi, dan pencatatan piutang usaha dan hutang usaha. Dalam hal ini kami ingin menjadikan mitra usaha Bika Bakar ini bisa layak dalam urusan pinjaman modal di lembaga keuangan/ perbankan.

Dalam pelatihan tentang strategi pemasaran merek dan Packaging, pembuatan merek untuk Bika Bakar menjadi pemicu pelaku usaha dalam mengikuti pelatihan ini, karena selama ini usaha Bika Bakar Bu Nurmalis belum ada sama sekali tercantum merek. Salah satu alasannya adalah takut dikenakan retribusi pajak, padahal merek itu sangat penting bagi usaha seperti karena usaha Bika Bakar yang ada di Medan masih sangat sangat jarang. Maka dari itu tim pengabdian memberikan bantuan dalam bentuk pembuatan design logo merek untuk produk tersebut. 


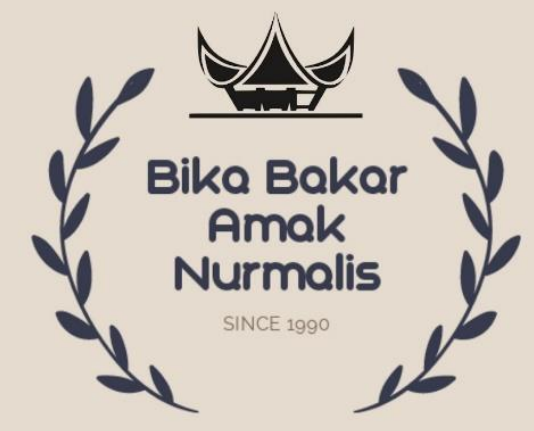

\section{gambar 1 . Merek yang sudah di desain tim Pengabdian}

Disamping itu juga, pelatihan ini juga menawarkan bagi pelaku usaha Bika Bakar untuk mengganti plastik yang digunakan untuk pembungkus Bika Bakar tersebut dengan memakai Paper Bag. Kemasan yang lebih menarik,lebih sehat bagi konsumen, dan Bika Bakarnya jadi lebih lama Panasnya. Hasil survey dipasar setelah adanya kemasan baru dan merek baru "BIKA BAKAR AMAK/ BUNDO Nurmalis".
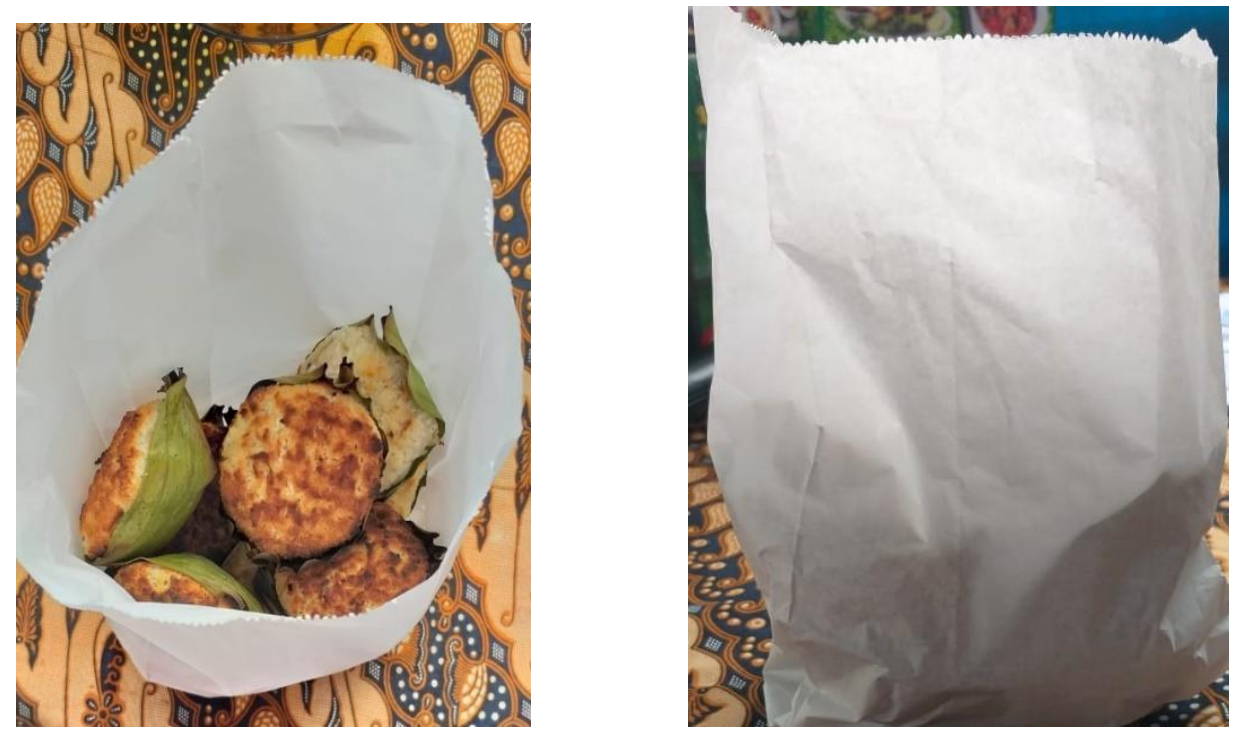

gambar 2 . packaging sudah menggunakan paper bag

Permasalahan yang terakhir adalah banyaknya pesanan di waktu tertentu membuat usaha $\mathrm{Bu}$ Nurmalis tidak dapat memenuhi pesanan tersebut. Maka dari itu kami memberikan bantuan juga berupa 2 Tungku api agar produksi dari Bu Nurmalis dapat meningkat dan memenuhi pesanan yang ada,serta cetakan kue Bika Bakar untuk mendukung kuantitas produk yang dihasilkan lebih maksimal. 


\section{Kesimpulan}

Kegiatan pengabdian yang telah dilaksanakan tim meliputi kegiatan pelatihan dan pendampingan dalam aspek penyusunan laporan keuangan, branding produk serta aktivitas pemasaran dengan memanfaatkan berbagai media online dan peningkatan kualitas dan kuantitas produksi. Dengan kerjasama tim pengabdian yang solid dan peran aktif para pemateri dalam pengabdian ini maka semuanya berjalan sesuai dengan diharapkan dan dapat memberikan manfaat bagi mitra pengabdian masyarakat dalam mengembangkan pangsa pasar Bika Bakar. Selain itu, tim pengabdian memberikan bantuan berupa alat bantu penunjang produksi yang akan membantu mitra meningkatkan kualitas produksi. Kegiatan pengabdian ini menargetkan peningkatan pendapatan masyarakat melalui pemberdayaan mitra pengabdian dan masyarakat sekitar

\section{DAFTAR PUSTAKA}

Kasmir, 2014. Analisis Laporan Keuangan, Edisi Pertama, Cetakan Ketujuh. Jakarta: PT. Rajagrafindo Persada.

Kotler, Philip, dan Gary Armstrong 2012. Prinsip-prinsip Pemasaran. Edisi 13. Jilid 1. Erlangga : Jakarta.

Suryana. (2014). Kewirausahaan. Jakarta: Salemba Empat 